\title{
Integration of Renewable Energy in Markets: Analysis of Key European and American Electricity Markets ${ }^{1}$
}

\author{
Hugo Algarvio ${ }^{1,2}$, Fernando Lopes ${ }^{1}$, João Santana ${ }^{2,3}$ \\ ${ }^{1}$ LNEG-National Laboratory of Energy and Geology, \\ Estrada do Paço do Lumiar 22, 1649-038 Lisboa, Portugal \\ fernando.lopes@lneg.pt \\ ${ }^{2}$ Instituto Superior Técnico, Avenida Rovisco Pais 1, 1049-001 Lisboa, Portugal \\ \{hugo.algarvio,jsantana\}@tecnico.ulisboa.pt \\ ${ }^{3}$ INESC-ID, Rua Alves Redol, 9, 1000-029 Lisboa, Portugal
}

\begin{abstract}
Electricity markets are systems for affecting the purchase and sale of energy. Most existing markets are built on well-established principles of competition and transparency. However, their designs are based on centralized power plants with a small participation of end-use customers. During the past years, the share of electricity produced by renewable sources increased significantly. This paper analyses the structure and operation of two European markets and two American markets. The analysis highlights that the design, rules and characteristics of most markets are still not completely adapted to power systems with high levels of variable renewable energy. Accordingly, the paper proposes some recommendations to foster the integration of renewable generation.
\end{abstract}

Keywords: Energy markets; market operation; renewable generation; market design.

\section{Introduction}

In the world, Power system have evolved from traditional vertically monopoly structures to liberalized markets that encourage competition between suppliers and consumers of electricity. Deregulation led to a completely different industry with novel competitive wholesale and retail markets based on open-access rules (see, e.g., [1]).

Most existing energy markets are built on well-established principles of competition and transparency. In particular, the design of European markets is founded on the measures of the Third Energy Package, approved in 2009 [2].

1 This work was supported by "Fundação para a Ciência e Tecnologia" with references UID/CEC/50021/2013 and PD/BD/105863/2014 (H. Algarvio). 
Broadly speaking, the Third Energy Package was very important for market participants. Yet, its rules are based on fuel-based power plants-that is, the predominant generation technologies of the last decade. The electricity system of Europe changed profoundly since 2009. The share of electricity produced by renewable sources is expected to grow up to $27 \%$ in 2030 . Accordingly, the Clean Energy for all Europeans adopted at the end of 2016 introduces further modifications in the energy market design [3].

Against this background, this paper analyses two key European markets: Nord Pool [4] and MIBEL [5]. Nord Pool is the Nordic electricity exchange, which includes three different markets: Elspot, Elbas and Eltermin. Elspot and Elbas are markets for the physical trade of energy, while Eltermin is a market for financial trade of energy. The Iberian Electricity Market (MIBEL) is the result of the cooperation between the Portuguese and the Spanish Governments with the aim of promoting the integration of the electrical systems of both countries.

The paper also analyses two key American markets: NYISO [6] and PJM [7]. NYISO (the New York Independent System Operator) coordinates the markets from the heart of Manhattan to the remote stretches of the Adirondack wilderness. PJM (the system operator of Pennsylvania, New-Jersey and Maryland) coordinates the markets from Delaware and Illinois to West Virginia and the District of Columbia.

All of these markets are unique and quite complex. Also, they were initially designed without taking into account the increasing levels of variable renewable energy (see, e.g., [8, 9]). Accordingly, this paper analyzes several key features of these markets to determine, at least to a certain extent, if their rules are appropriate to the new market realities.

The remainder of the paper is structured as follows. Section 2 describes the structure and operation of real-world energy markets generally. Section 3 describes in detail the four aforementioned energy markets. Section 4 analyses the key features of the four markets. Finally, section 5 presents some concluding remarks and describes avenues for future work.

\section{Relationship to Industrial and Service Systems}

As noted, this work analyses four real-world markets in terms of structure and operation. Accordingly, the relationship of the work with industrial and service systems is clear and natural. It is also worth mentioning that the participants in wholesale energy markets are typically industrial companies.

European Markets. In terms of structure, European markets usually include dayahead markets, intra-day markets and bilateral markets (see, e.g., [10]). Day-ahead markets (DAMs) are markets based on auctions. Energy is traded at 12 noon of the day before the day of operation. The pricing method is based on the marginal pricing theory. Intra-day markets may be based on auctions or operate continuously. These markets allow the parties to refine their positions a few hours ahead of real-time. 
Bilateral markets allow to hedge, at least in part, against the risk inherent to dayahead and intra-day markets. Market participants may negotiate the price (and "adjust" the quantity) of various types of standardized contracts, notably forward contracts, future contracts, options and contracts for difference [10].

In addition to the aforementioned markets, the so-called "balancing markets" allow the participation of specific market participants at short notice. Such markets represent the key mechanism for fixing the imbalances relative to the physical settlement on both day-ahead and intra-day markets. Typically, the transmission system operator (TSO), a non-commercial organization, independent of commercial players, constitutes the demand side. Balance responsible parties (BRPs) represent the supply side and sign a pre-agreement on balance responsibility with the TSO. BRPs with available generation capacity submit up-regulation orders to the TSO. Likewise, BRPs able to reduce consumption submit down-regulation orders to the TSO. All regulating power orders are ranked with increasing price. In case the TSO is procuring up regulation, the up-regulation orders with lowest prices are activated until the procured quantity is reached. The price of the last up-regulated order sets the upregulation price. The orders with prices below the up-regulation price have a profit, defined by the difference between the final price and the offered price. A similar procedure is used to set the down-regulation price.

Following the definition of up-regulation and down-regulation prices, the TSO performs an imbalance settlement process. Basically, the participants that cause system imbalances should contribute to the payment of the costs for re-establishing the balance of the system. In this way, players should ensure that they trade electrical energy according to specific plans. Deviations from plans add up to the net imbalances and typically involve the payment of penalties.

American Markets. Most American markets include a DAM and a short term market, generally referred to a real-time market (RTM). This design reflects a twosettlement system. The DAM defines prices and schedules for an entire day, one day in advance, based on the locational marginal pricing theory. The RTM is a 5-min market where participants can refine their positions a few minutes before real-time. The average prices of the DAM and RTM should converge, to avoid speculation and a preference for any of the two markets (see, e.g., [11]).

\section{Key Electricity Markets}

\subsection{European Markets: Nord Pool and MIBEL}

In Nord Pool, the day-ahead market (Elspot) accepts several types of orders, including single hourly orders, block orders, exclusive groups and flexi orders. Customers can use any type of orders or a combination of different types to meet their requirements. The market closes at 12:00 CET and area prices (as well as the system price) are calculated for each delivery hour. It allows aggregated bids. The intra-day market (Elbas) supplements the day-ahead market and provides some flexibility to participants by offering $15-\mathrm{min}, 30-\mathrm{min}$, hourly and hour-blocks products. This 
market is based on continuous trading, meaning that the orders are matched automatically when concurring offers are registered in the trading platform, typically up to one hour before the delivery hour $[12,13]$.

Nord Pool includes a balancing market that consists of a regulating power market and a balancing power market. In the regulating power market, TSOs buy/sell power from/to BRPs in the delivery hour taking into account the bids performed for upward and downward regulation. Bids refer to the next day of operation $(d)$ and may or may not cover the entire day. Typically, bids are submitted until 17:00 of day $d-1$ and can be adjusted after the clearing of the intraday market, up to 45 -minutes before the delivery hour. The price of regulating power (RP price) is determined according to the marginal pricing theory and calculated on an hourly basis [14].

On the balancing power market, TSOs buy/sell power from/to market participants in order to balance the system. The settlement basis for balancing power is constituted by BRP notifications submitted to TSOs. Notifications are submitted during day $d-1$ and may be adjusted during the day of operation $(d)$ as a result of intra-day and bilateral trades. The balance settlement is based on the difference between production (and/or consumption) compared to the submitted notifications. Two models for settlement of balancing power are used: the one-price model and the two-price model [14].

The Daily Iberian market (day-ahead market) sets prices for electrical energy every day at 12 noon, by considering EUPHEMIA, an algorithm based on the marginal pricing model adopted by the European Union. Generating companies, retailers and other market participants may trade energy regardless of whether they are in Spain or in Portugal. Bids are accepted according to the merit order, until the interconnection between Portugal and Spain is fully occupied. In such a case, there will be a different price of electricity for Portugal and Spain. Otherwise, the price will be the same for both countries. The DAM does not allow aggregated bids. The intra-day market runs after the DAM and involves six trading sessions, based on auctions. This market permits agents to readjust their commitments for purchasing and selling energy up to 4 hours ahead of real time. As of that moment, there are other markets managed by the TSOs in which a balance is struck at all times between production and consumption [15].

The system operators of Portugal and Spain identify separately situations when they consider necessary to modify the schedules to ensure the quality and security of the electricity supply, and also to guarantee a constant balance of the power system. To this end, they make use of ancillary services, which may be roughly divided into: (i) mandatory services, namely primary frequency and voltage control and (ii) voluntary services, notably secondary and tertiary frequency control, voltage control and service refurbishment. In Portugal, the submission of offers for tertiary regulation should be done until 8:00 p.m. of day $d-1$. The offers may be adjusted up to 20 minutes after the publication of the final hourly program of the different intra-day sessions [16]. 


\subsection{American Markets: NYISO and PJM}

NYISO manages a day-ahead market and a real-time market, resulting in a twosettlement power system that defines prices and quantities of electricity based on the locational marginal pricing theory. The DAM closes at 5:00 a.m. of day $d-1$ and the prices resulting from a security constrained unit commitment process are posted until 11:00 a.m. of the same day. The RTM closes 75-minutes prior to the operating hour and is based on real-time offers. The clearing of the market is settled 45 minutes before the delivery hour. The RTM allows agents to refine their positions in relation to the DAM settlement. The real-time dispatch involves blocks of 5 minutes (for each hour $h$ ), i.e., executes periodically on a 5 -minute basis and defines the corresponding prices. DAM schedules are balanced against "actual" usage and differences are settled taking into account real-time prices [17].

NYISO considers various ancillary services, notably regulation and frequency response, operating reserve and energy imbalance. Regulation service qualified suppliers submit bids into the day-ahead and real-time regulation services markets. For the day-ahead regulation services market, NYISO establishes the regulation capacity requirements according to the standards established by the North American Electric Reliability Council. Ancillary services are scheduled on an hour basis. Bids may be submitted up to 75-minutes prior to the delivery hour [18].

The energy market of PJM is divided in two markets, a day-ahead market and a real-time market. The DAM closes at 10:30 of the day before the day of operation and the results are announced at 13:30. The RTM is a 5-minute market based on actual real-time operation. Participants may submit bids until 65-minutes prior to the delivery hour [19].

The Regulation Market of PJM allows participants to trade specific ancillary services. Daily regulation offers must be submitted prior to 14:15 (of the day before the day under consideration) and cannot be negative. These offers can be changed until 65-minutes prior to the delivery hour [19].

\section{Analysis of Key Markets}

Tables 1 and 2 summarize the most important features of the day-ahead and intraday/real-time markets of Nord Pool, MIBEL, NYISO and PJM. The harmonization of European day-ahead markets is at an advanced stage. The main differences between most markets are related to price caps and the possibility of submitting aggregated bids. However, the harmonization of European intra-day markets is still at an early stage. The main differences between most markets are related to the gate closure, the market time unit, the trading type, the pricing mechanism, the price caps and the possibility of submitting aggregated bids. 
Table 1. Key day-ahead markets: summary of features.

\begin{tabular}{lllll}
\hline Feature & Elspot & MIBEL & NYISO & PJM \\
\hline Gate Closure & $\begin{array}{l}12-37 \\
\text { hours ahead }\end{array}$ & $\begin{array}{l}12-37 \\
\text { hours ahead }\end{array}$ & $\begin{array}{l}19-43 \text { hours } \\
\text { ahead }\end{array}$ & $\begin{array}{l}13.5-37.5 \text { hours } \\
\text { ahead }\end{array}$ \\
Time Unit & 1 hour & 1 hour & 1 hour & 1 hour \\
Trading Type & Auction & Auction & Auction & Auction \\
Pricing & Locational & System Marginal & Locational & Locational \\
Mechanism & Marginal Pricing & Pricing & Marginal Pricing & $\begin{array}{l}\text { Marginal Pricing } \\
\text { Product Type }\end{array}$ \\
\hline
\end{tabular}

Table 3 summarizes the main features of key balancing markets associated with Nord Pool and MIBEL. The harmonization of European balancing markets is also at an early stage. The differences between markets are significant.

Now, variable renewable energy (VRE), such as solar and wind power, has increased significantly during the past years. VRE brings uncertainty to the net load, and also near-zero variable costs, but significant fixed costs. To accommodate the increasing levels of renewable generation, electricity markets should ideally account for the following:

1. aggregated bids (e.g., bid from various wind power producers);

2. a gate-closure close to real-time operation (e.g., a few minutes ahead);

3. the participation of wind power producers in balancing markets;

4. a shorter time unit (e.g., 15 minutes);

5. new market products adapted to the increasing levels of renewable generation.

The aforementioned European and American markets do not comply with all of these characteristics. For instance, European markets consider reasonable gateclosures (ranging from 3 hours, in the intra-day European market, to 5 minutes, in Elbas), but large time units (ranging from 4 hours, in the German balancing market, to 15 minutes, in Elbas). Also, American markets should consider gate-closures closer to real-time operation.

Table 2. Key intra-day and real-time markets: summary of features.

\begin{tabular}{|c|c|c|c|c|}
\hline Feature & Elbas & MIBEL & NYISO & PJM \\
\hline Gate Closure & 5-60 mins ahead & $2-3$ hours ahead & 75 mins ahead & 65 mins ahead \\
\hline Time Unit & $15-60 \mathrm{mins}$ & 1 hour & $5 \mathrm{~min}$ & $5 \mathrm{~min}$ \\
\hline Trading Type & Continuous & Auction & Auction & Auction \\
\hline $\begin{array}{l}\text { Pricing } \\
\text { Mechanism }\end{array}$ & $\begin{array}{l}\text { Pay-as-bid } \\
\text { (auction also for } \\
\text { Germany) }\end{array}$ & $\begin{array}{l}\text { System } \\
\text { Pricing }\end{array}$ & $\begin{array}{l}\text { Locational } \\
\text { Marginal Pricing }\end{array}$ & $\begin{array}{l}\text { Locational } \\
\text { Marginal Pricing }\end{array}$ \\
\hline Product Type & Capacity & Capacity & Capacity & Capacity \\
\hline
\end{tabular}


Table 3. Key balancing markets: summary of features.

\begin{tabular}{lllll}
\hline Feature & Nord Pool & REN & NYISO & PJM \\
\hline Gate Closure & $7-31$ hours ahead & $1-24$ hours ahead & 75 min ahead & 1 hour ahead \\
Bid Adjustment & 45 mins ahead & $1-3$ hours ahead & 1 hour & 1 hour \\
Trading Type & Auction & Auction & Auction & Auction \\
Product Type & Capacity & Capacity & Capacity & Capacity \\
\hline
\end{tabular}

\section{Conclusion}

This paper has analyzed two important European electricity markets: Nord Pool and MIBEL. The paper has also described two key American markets: NYISO and PJM. Several conclusions can be drawn from the analysis. The harmonization of day-ahead markets, particularly for the case of European markets, is already at an advanced stage. However, the harmonization of European intra-day markets is still at an early stage. In relation to the European balancing markets, there are still significant differences between them, and the harmonization is also at an early stage.

We can state, at least to some extent, that the design, rules and characteristics of the analyzed markets are still not (completely) adapted to power systems with large levels of variable renewable energy. Accordingly, State Regulators should focus on the following five aspects:

1. The active participation of variable generation in markets.

2. The possibility of aggregated bids.

3. The consideration of gate-closures closer to real-time.

4. Shorter markets time units.

5. New products adapted to variable generation.

These aspects can be considered very important to increase the efficiency of power systems with increasing levels of variable renewable energy.

\section{References}

1. Lopes, F., Coelho, H.: Electricity Markets with Increasing Levels of Renewable Generation: Structure, Operation, Agent-based Simulation and Emerging Designs. Springer International Publishing, Cham, 2018. https://doi.org/10.1007/978-3-319-74263-2 (Cited on 15 February, 2019)

2. EC: Directive 2009/72/EC of the European Parliament and of the Council. Official Journal of the European Union, L 211/55--L 211/93 (2009)

3. EC: Proposal COM (2016) 861 for a Regulation of the European Parliament and of the Council on the Internal Market for Electricity. Brussels (2017)

Nord Pool. https://www.nordpoolspot.com/

Iberian Electricity Market. http://mibel.com/en/home_en/

New York Independent System Operator. http://www.nyiso.com/

PJM. https://www.pim.com/

Skytte, K., Grohnheit, P.: Market Prices in a Power Market with More Than 50\% Wind Power, In: Electricity Markets with Increasing Levels of Renewable Generation: Structure, Operation, Agent-based Simulation, and Emerging Designs, pp. 81--94, Springer International Publishing, Cham, 2018. https://doi.org/10.1007/978-3-31974263-2_4 (Cited on 15 February, 2019) 
9. Ela, E., Milligan, M., Bloom, A., Botterud, A., Townsend, A., Levin, T.: Incentivizing Flexibility in System Operations, In: Electricity Markets with Increasing Levels of Renewable Generation: Structure, Operation, Agentbased Simulation, and Emerging Designs, pp. 95--127, Springer International Publishing, Cham, 2018. https://doi.org/10.1007/978-3-319-74263-2 5 (Cited on 15 February, 2019)

10. Lopes, F., Coelho, H.: Electricity Markets and Intelligent Agents Part I: Market Architecture and Structure. In: Electricity Markets with Increasing Levels of Renewable Generation: Structure, Operation, Agent-based Simulation and Emerging Designs, pp. 23--48, Springer International Publishing, Cham, 2018. https://doi.org/10.1007/978-3-319-74263-2_2 (Cited on 15 February, 2019)

11. Ela, E., Milligan, M., Bloom, A., Cochran, J., Botterud, A., Townsend, A., Levin, T.: Overview of Wholesale Electricity Markets. In: Electricity Markets with Increasing Levels of Renewable Generation: Structure, Operation, Agent-based Simulation and Emerging Designs, pp. 3--21, Springer International Publishing, Cham, 2018. https://doi.org/10.1007/978-3-319-74263-2_1 (Cited on 15 February, 2019)

12. Nord Pool: Day-ahead Market Regulations. Nord Pool AS (15 August 2017)

13. Nord Pool: Intraday Market Regulations. Nord Pool AS (12 June 2018)

14. Entsoe: Nordic Balancing Philosophy. European Network of Transmission System Operators (16 June 2016)

15. OMIE: Day-Ahead and Intraday Electricity Market Operating Rules. OMI-Polo Español S.A. (11 May 2018)

16. ERSE: Manual de Procedimentos da Gestão Global do Sistema do Setor Elétrico. Entidade Reguladora dos Serviços Energéticos (Junho 2018)

17. NYISO: NYISO Markets: New York's Marketplace for Wholesale Electricity, New York Independent System Operator (2018)

18. NYISO: Ancillary Services Manual. New York Independent System Operator (April 2018)

19. PJM: Manual 11 - Energy \& Ancillary Services Market Operations. Pennsylvania-New Jersey-Maryland Independent System Operator (October 2018) 